\title{
Xylophagia: A meta-synthesis of the literature
}

\section{ABSTRACT}

3 Purpose: This review provides an insight into xylophagia, its treatment, intervention options, etiological causes, and

4 possible relationship with other diseases.

5 Design/methodology/approach: A systematic search was performed across four scientific databases (i.e., Ovid

6 Medline, Embase via Ovid, PubMed and ProQuest). All of the qualitative studies reporting on xylophagia from the

7 inception of databases until August 2019 have been included. The quality of included studies was assessed through a

$8 \quad$ 10-item checklist given by Kmet, Lee, and Cook in 2004.

9 Findings: A total of 18 studies were included, and five primary themes emerged after analysis: 1)

10 Precipitation/onset of xylophagia, 2) Co-morbid psychiatric or medical illnesses, 3) Assessment and investigation

11 modes to confirm diagnosis, 4) Outcomes of xylophagia, and 5) Treatment options comprising medical care,

12 psychological care, counselling, and duration of recovery. There were 16 females and 9 males in included studies.

13 The mean age and standard deviation of males and females were 29.25(12.17) years and 32.81(11.92), respectively.

14 The mean duration and standard deviation of paper pica were 4.80(4.27) years.

15 Research implications: Despite the limitation that this meta-synthesis is based upon findings from case studies, 16 results show that standardized medication regimens for treating xylophagia are still not available or unknown. There

17 is a dire need for further research in order to better understand the disorder. The healthcare professionals need to use

18 the reciprocal, mutually constituent influence of biological and sociocultural factors in order to screen, diagnose and 19 manage problems like xylophagia.

20 Originality/value: The findings advance our understanding of the positive effects of patients and family members 21 undergoing counselling or cognitive behavior therapy in reducing stress and enhancing coping skills thus avoiding 22 self-damaging behaviors has been established.

23 Keywords: Xylophagia, Pica, Eating Disorder, Psychosis, Health Services, Qualitative Research, Health Policy, 24 Quality of Care 


\section{Key Points}

27 1. This review provides an insight into xylophagia, its treatment and intervention options, possible etiological causes, 28 postulated relationships with other diseases and highlights its inclusion in differentials of a medico-legal 29 physician.

30 2. This paper highlights factors that lead to precipitation/onset of xylophagia, the co-morbid psychiatric or medical 31 illnesses, various assessment and investigation modes to confirm the diagnosis of xylophagia, the outcomes of 32 xylophagia, and various treatment options comprising medical care, psychological care, counselling, and duration 33 of recovery.

34 3. This review includes xylophagia studies from various countries and shows that xylophagia is multifaceted and 35 underdiagnosed.

36 4. There were females and males in included studies indicating its prevalence across gender.

37 5. This review suggests a need for biopsychosocial integration in diagnosing and treating eating disorders. 


\section{Introduction}

The simple act of eating has a certain cost as food has been shown to be the cause of millions of deaths

40 globally due to various mechanisms. The consumptions of hundreds of microbial, chemical and physical agents can 41 result in illness and have various lethal outcomes (Acheson, 1999, Jacob et al., 1990, Parakh et al., 2016, Dalal et al., 42 2013, Barros et al., 1991). The forensic pathologists frequently come across cases of death by food and occasional 43 and culturally-specific cases of death due to intentional or unintentional intake of pathogens, poisons, and foodstuffs 44 (Byard, 2017).

Xylophagia is described as the consumption of substances made up of wood such as paper, pencils, boxes, toothpicks, matches and tree barks; with paper ingestion the most frequently reported type (Gowda et al., 2014,

47 Moore and Sears, 1994). It is a form of pica, where a person has a developmentally inappropriate compulsive 48 yearning for and eats non-nutritive substances (Blinder and Salama, 2008). Pica is explained in the field of medicine 49 as an unnatural appetite that initiates a craving for unhealthy substances. Other kinds of pica comprise lithophagia 50 (stone eating), geophagia (dirt eating), ice (pagophagia), gravel, paint flakes, clay, hair (trichophagia), and laundry 51 starch (amylophagia) (Byard, 2014, Parry-Jones and Parry-Jones, 1992, Loots and du Toit-Prinsloo, 2016). There 52 has been much ambiguity in classification of this disorder, with the Diagnostic and Statistical Manual of Mental 53 Disorders version 5 (DSM-V) classifying it as an eating disorder in persons who fulfill the following criteria: 54 persistent eating of non-nutritive substances for a period of at least one month, the consumption of non-nutritive substance that is inappropriate to the developmental level of an individual, eating behavior that is not culturally

56 supported or socially practiced, or the behavior is severe enough to call for independent clinical attention if it occurs 57 along with another mental disorder or medical condition (APA, 2013). Others, however, have suggested that it is on 58 the obsessive-compulsive disorder (OCD) spectrum, given both the obsessive and compulsive features observed in 59 patients (Bhatia and Gupta, 2009, Gundogar et al., 2003, Hergüner et al., 2008).

A variety of factors are involved in the etiology of pica, such as genetic, biological, and particularly 61 sociocultural and nutria-physiological aspects (Rose et al., 2000, Levine and Smolak, 2014). Likewise, a past study 62 has suggested the integration of sociocultural and biopsychiatric factors in etiology and management of eating 63 disorders (Levine and Smolak, 2014). A study conducted on pregnant women in Mexico found that between 64 approximately $30-50 \%$ of the women consumed dirt, ashes, and clay; believing that failure to do so would lead to 
miscarriage (Simpson et al., 2000). A large part of the literature also attributes it to iron deficiency, although there

66 remains some controversy as to whether it is a cause instead of an outcome of iron deficiency (Kettaneh et al., 2005,

67 Gupta A et al., 2007). Other research studies have highlighted the role of social and religious customs, where pica is

68 considered culturally-acceptable and is thus not viewed as pathological (Blinder and Salama, 2008). This ambiguity

69 has then resulted in confusion as to how this condition should be treated. A review paper highlighting the forensic

70 implications of pica (Byard, 2014) shows that various fatal mechanisms result in the death of a person with pica. In

71 case of suspicion of pica in persons who are institutionalized or have developmental delay, post-mortem

72 examinations should cautiously analyse the possible side effects of eating non-food substances (Byard, 2014).

73 Authors highlight the presence of minimal presenting symptoms and signs due to a variety of reasons.

In children aged between 18 to 36 months, an incidence of pica greater than 50\% is considered normal, and this is thought to decrease with age (Blinder and Salama, 2008). Among institutionalized patients, prevalence rates range from 4-26\% (Walker and M.C. Roberts, 2001), and it was noted that from 1999 to 2009, hospitalization rates due to pica increased by more than $90 \%$ (Zhao and Encinosa, 2011). The intake of foreign bodies is commonly observed in children and certain susceptible adult populations such as alcoholics, the elderly with dentures, prisoners, and individuals with psychiatric problems (Yamaguchi et al., 2014, Zouros et al., 2014, Cangir et al., 2002, Velitchkov et al., 1996).

In most of the cases, the autopsy results reveal accidental intake of foreign bodies (e.g., meat or bones). In rare cases, the autopsy results reveal non-food components (e.g., teeth, glass fragments, dental crowns, batteries, or

83 small toys) (Sreetharan et al., 2004), and suicidal intent must be considered when children or inebriated patients are 84 involved in ingesting these substances (Krugman et al., 2007, Žganjer et al., 2011, Bloch et al., 2005, Nicolai and 85 Reiter, 2004). There is a need for thorough knowledge and sufficient medico-legal experience in order to 86 differentiate between suicidal acts and homicide (Sauvageau and Racette, 2006). Furthermore, in rare cases of drug 87 abuse and eating disorders, there is an intake of non-food substances (Schaper et al., 2003).

The past empirical studies in various cases have shown that the intake of non-food pica (depending on the 89 type, number, and size of the objects) leads to adverse health outcomes (e.g., aggressive periodontitis, lead 90 poisoning, phosphorus poisoning, dental damage, mercury poisoning, nicotine poisoning, toxocara infections, 91 hemolytic anemia, electrolyte disturbances, blockage, hemorrhage, and tamponade from vessel and heart 
92 perforation, and sepsis) due to failure to digest the foreign substances (McLoughlin, 1988, Decker, 1993, Johnson,

93 1990, Federman et al., 1997, Glickman et al., 1981, Toker et al., 2009, Advani et al., 2014, Kar et al., 2015, Byard,

94 2000, Byard, 2014). The past empirical evidence has shown death due to: vagal stimulation with resultant cardiac

95 arrhythmia, intestinal causes, and intestinal obstruction in some cases of pica (Wick et al., 2006, Byard, 2014). The

96 intake of hair or paper may form bezoars which lead to intestinal obstruction due to absorption of fluid in the

97 accumulated paper in the colon area (Byard, 2014). The presence of non-food substances in the aerodigestive tract of

98 children at post-mortem examination is not always indicative of pica as the children may have intentionally or

99 unintentionally eaten foreign material (Byard et al., 1990, Yamaguchi et al., 2014, Zouros et al., 2014). The variety

100 of outcomes of pica and lack of specificity has added to the problems in diagnosing pica. The cultural

101 contextualisation of eating disorders, as proposed in a past study (Levine and Smolak, 2014) needs to be

102 comprehensively assessed.

103 As it pertains to xylophagia specifically, there is a paucity of data available due to differences in definitions

104 as well as reluctance on the part of patients to admit to it (Blinder and Salama, 2008), further thwarting efforts to

105 diagnose, prevent, and manage this disease comprehensively and effectively. Hence, there is ambiguity on the

106 etiology of xylophagia and limited empirical evidence on the fatal or potentially fatal outcomes of xylophagia. Thus,

107 this meta-synthesis was undertaken as an attempt to fill this gap, and provide a better understanding on xylophagia,

108 its treatment, possible causes and postulated relationship with other diseases. A meta-synthesis is a systematic

109 reviewing process that combines and analyses qualitative evidence in a coherent manner, with the primary purpose

110 of developing a deeper understanding of a particular phenomenon (Erwin et al., 2011, Walsh and Downe, 2005,

111 Campbell et al., 2003, Jensen and Allen, 1996). This meta-synthesis was of descriptive type as it analyzed the

112 phenomenon of xylophagia comprehensively.

\section{Methods}

114 A systematic exploration of the qualitative empirical literature on xylophagia was carried out. Our focus was

115 on gaining a better understanding of xylophagia, its prevention, treatment and intervention options, possible

116 etiological causes and postulated relationship with other diseases. Therefore, meta-synthesis approach was used to

117 assimilate and synthesize research studies related to xylophagia. 
Search strategy. We carried out a thorough search strategy for finding related research studies (see Figure 1

119 PRISMA flow diagram). Using the keywords including xylophagia, paper eating, paper pica, and paper bezoar, we 120 explored electronic databases including Ovid Medline, Embase via Ovid, PubMed, and ProQuest. We also manually 121 searched reference lists of all the retrieved research studies for potentially related documents.

122

\section{See Figure 1}

Inclusion/exclusion criteria. In order to identify the eligibility of research studies included in our metasynthesis, we applied the inclusion and exclusion criteria on the titles, citations, and abstracts of retrieved articles. The search was updated to retrieve any study published between the dates of databases' inception until August 2019. The inclusion criteria were: Qualitative studies published in peer-reviewed journals, letters to editors discussing cases of xylophagia and related brief reports. Studies related to xylophagia but no other forms of pica were selected. No restriction was made on the population being served. The exclusion criteria were: quantitative studies, literature reviews, articles written in a language other than English, and grey literature. The authors (KM, YMA, YZ, TMK, LT, FSB, and FRC) thoroughly reviewed each research article for inclusion in the meta-synthesis. The discrepancies were resolved through mutual discussion until a consensus was attained.

Quality assessment. If a review comprises research articles of low quality, the findings of review may be flawed, thereby endangering its reliability (Walsh and Downe, 2006). The quality of all the included studies was assessed using the 10-item criteria checklist given by Kmet, Lee, and Cook (Kmet et al., 2004). An overall rating ranging from 0 to 1 was assigned to every article; higher ratings were an indicator of higher quality. The lowest quality ratings of included studies in the present review were 0.2 , we considered all studies adequate for inclusion in this review. (See Table 1, column "score in quality assessment", and Online Resource; Supplementary Table 1 for “Quality rating of included studies").

See Table 1

Analytic strategy. In order to review the research studies, we followed Noblit and Hare's 7-step approach for synthesizing from qualitative studies (Noblit and Hare, 1988). This approach consists of these steps: searching eligible studies that fulfill inclusion criteria; screening retrieved literature; reading studies and extracting data; 
147 determining how the studies are related; translating the studies into one another; synthesizing translation; and 148 expressing the translation (Hines, 2013, Noblit and Hare, 1988). We began with reviewing every research study

149 various times in order to recognize and record main themes along with details pertaining to the context of the study.

150 We carried out a first order construct which involved making a data table for identifying main ideas and concepts 151 throughout the research articles. This helped in finding the ways in which all research articles were related to one 152 another. We then carried out second-order constructs. In this step, the finding of every research article was 153 compared and contrasted systematically to identify points of convergence and divergence. This also helped us in 154 matching themes across studies and formulating categories of themes. Additionally, we ensured that all the themes 155 paralleled the overall line of argument relating to xylophagia that arose from our review.

156 Results

157 A total of 18 articles were included in this meta-synthesis. The characteristics of the 18 cases studies are 158 shown in Table 1. This meta-synthesis comprises 14 case reports, 3 letters to editors and 1 experimental study. 159 Seven studies reported cases of xylophagia from United States of America (US); two studies were carried out in 160 India, one in Iran, Ireland, Germany, United Kingdom, Canada, South Africa, Greece, Australia, and Turkey 161 respectively. There were 16 females and 9 males in included studies. The mean age and standard deviation of males 162 and females were 29.25(12.17) years and 32.81(11.92), respectively. The mean duration and standard deviation of 163 paper pica were 4.80(4.27) years.

164 Summary of synthesis. Five primary themes emerged from our meta-synthesis: 1) Precipitation/onset of 165 Xylophagia, 2) Co-morbid psychiatric or medical illnesses, 3) Assessment and diagnostic methods, 4) Outcomes of 166 xylophagia, and 5) Treatment options. The distribution of themes across the 18 papers is detailed in Figure 2. Table 1672 shows selected data excerpts from included articles.

168
See Figure 2

See Table 2 

of xylophagia, and in particular modelling of this behavior through vicarious learning (Bharti et al., 2015) including

177 the symptom of celiac disease (Fotoulaki et al., 2007).

Family history: Some of the family members of xylophagia patient were reported as having a paper-eating 179 habit before their onset (Bharti et al., 2015).

Duration: Some patients started eating paper or cardboard in order to escape from painful experiences and avoid reality. Duration of consumption was varied, with some reporting more than a year (Chisholm Jr and Martín,

182 1981), two to three years (Bharti et al., 2015, Gowda et al., 2014, Yalug et al., 2007), five years (Callinan and 183 O'Hare, 1988), and 12 years (Olynyk and Sharpe, 1982). There were also adults who started from adolescence 184 (Olynyk and Sharpe, 1982), while others started late in life (Dumaguing et al., 2003).

Maintaining factors: Various factors were found playing a role in the continuation and maintenance of this behavior. For instance, one study revealed that paper eating alone, learned through instrumental learning, was

187 reinforced and maintained through escape learning. It progressed due to a lack of attention from family members 188 (Bharti et al., 2015). Another study showed that paper eating became a pattern as the patient used to eat paper alone 189 without anyone noticing the odd behavior, thus leading to persistent xylophagia (Gowda et al., 2014). Similarly, 190 distorted beliefs about body image, traumatic family history, the pressure of family responsibility, and lack of 191 amiable relations with a parent played a vital role in onset and continuation of paper eating (Yalug et al., 2007). The

192 habit of eating cardboard also progressed in order to lose weight, control food intake, and attain satiety; as well as to 193 reduce tension and achieve gratification (Callinan and O'Hare, 1988, Stein et al., 1996). Looking as a whole, these 194 findings show an intricate interplay of psychological factors behind increasing vulnerability, acting as precipitating 195 factors as well as maintaining factors of xylophagia.

\section{2) Co-morbidity}

Psychological disorders: These include inhalant use disorder (Gowda et al., 2014), alcohol dependence 198 (Moore and Sears, 1994), schizophrenia (Klein et al., 2014), bsessive-compulsive disorder (Bharti et al., 2015), 199 intellectual disabilities (Keeling et al., 1987); anorexia nervosa, major depressive disorder, panic disorder with 
agoraphobia, social phobia, pica, and hair-pulling (Bakhshaeekia et al., 2009, Spaniolas et al., 2010, Stein et al., 201 1996, Yalug et al., 2007).

Medical diseases: These include: Mercury poisoning (Olynyk and Sharpe, 1982); anemia (Callinan and

203 O'Hare, 1988); coeliac disease (Fotoulaki et al., 2007); gastritis and duodenitis (Moore and Sears, 1994). These

204 findings reveal that understanding xylophagia is problematic because its symptomatology is complicated by the 205 presence of various co-morbid psychological and medical disorders.

\section{3) Assessment and diagnostic methods}

Medical assessment/laboratory examinations/dietary history: Individuals with xylophagia present meta-synthesis reveals that medical specialists employed a complex array of testing procedures, for instance, abdominal x-ray, exploratory laparotomy (Bakhshaeekia et al., 2009); emogram, serum electrolytes, and serum iron

212 full blood count, blood film, white blood cell count, serum iron level, liver function test results, levels of serum 213 protein, albumin, calcium, phosphate, urea, and electrolytes, blood glucose levels, and thyroid function

214 measurements (Callinan and O'Hare, 1988). Similarly, diagnosticians have also employed dietary history, hematocrit 215 level test, hemoglobin level test, corpuscular hemoglobin test, corpuscular hemoglobin count test, and serum zinc 216 test (Chisholm Jr and Martín, 1981); Cognitive functions, physical examination, complete blood picture, urine 217 routine and X-ray abdomen, liver function, peripheral blood smear examination (Gowda et al., 2014, Moore and 218 Sears, 1994); and many more (Graham, 1976, Keeling et al., 1987, Klein et al., 2014, Olynyk and Sharpe, 1982, 219 Schmocker et al., 2015, Spaniolas et al., 2010, Stein et al., 1996, Yalug et al., 2007).

\section{4) Outcomes of xylophagia}

Symptoms/psychological problems/health impact: A number of medical complications were reported, such

222 as bowel perforation, cachectic and malnourishment, disturbed smell and loss of taste senses, abdominal pain, 223 headaches, dyspnea on exertion, chronic fatigue and listlessness, colonic ischemia, peritonitis and intestinal 224 perforation, retinitis pigmentosa, recurrent hypochromic, microcytic anemia, intestinal obstruction, and death 225 (Bakhshaeekia et al., 2009, Bharti et al., 2015, Callinan and O'Hare, 1988, Chisholm Jr and Martín, 1981, Graham, 
226 1976, Keeling et al., 1987, Klein et al., 2014, Moore and Sears, 1994, Olynyk and Sharpe, 1982, Schmocker et al., 227 2015, Fisher, 2014, Spaniolas et al., 2010, Uretsky, 1974). Various psychological problems reported include 228 anhedonia, weeping spells, thoughts about committing suicide, restlessness, anxiety, palpitations, insomnia, loss of 229 appetite, reduction in attention and concentration, anger outbursts, stubbornness, and self-mutilating behaviors 230 (Bharti et al., 2015, Gowda et al., 2014). Quality of life was also impacted, with reports of decreased interest in 231 personal and social life, reduced interaction with family members and friends, reduction of interest in pleasurable 232 activities, poor academic performance, and slacking in household chores (Bharti et al., 2015, Gowda et al., 2014).

Pleasurable effects: One patient reported that eating paper resulted in feelings of satiety resulting in a 234 reduction in food intake and weight, which then pleased the patient (Callinan and O'Hare, 1988). Similarly, eating 235 notebook paper and newspapers was shown to be the source of immense pleasure (Gowda et al., 2014, Stein et al., 236 1996). However, this is not the case as one study reported a lack of pleasure from this habit (Bharti et al., 2015).

\section{5) Treatment options}

238 Medical care: Medical treatments recommended by the included studies comprised: prescribing drugs, 239 surgeries or supplements, such as fluoxetine (Bharti et al., 2015); iron dextran intravenous infusion, folic acid and 240 vitamin $\mathrm{B}_{12}$ injections (Callinan and O'Hare, 1988); elemental zinc and ferrous sulphate (Chisholm Jr and Martín, 241 1981); paroxetine, clonazepam, baclofen, supplemental multi-vitamin injectable preparations (Gowda et al., 2014); 242 upper gastrointestinal series, upper endoscopy, iron supplementation (Schmocker et al., 2015); clomipramine, 243 sertraline, citalopram (Stein et al., 1996); olanzapine, fluoxetine (Yalug et al., 2007); and oral ferrous sulphate 244 therapy (Moore and Sears, 1994, Olynyk and Sharpe, 1982).

Psychological care/counselling: Psychotherapy was employed in four studies, which included

246 psychoeducation for patients and family members, cognitive behavior therapy (CBT) to reduce stress, enhance 247 coping skills, restructure disturbing cognitions, and avoiding damaging behaviors (Bharti et al., 2015, Gowda et al., 248 2014), overcorrection (Foxx and Martin, 1975), and counselling regarding the disease and appropriate eating 249 behaviors (Schmocker et al., 2015).

Recovery rates and duration: The findings revealed improvements in symptoms and in some cases patients were reported to be asymptomatic. Improvements in symptoms, no recurrence and aversion towards paper/cardboard 
252 eating was seen from a minimum of one week of treatment and ranged to variable time durations of follow-ups 253 (Callinan and O'Hare, 1988, Chisholm Jr and Martín, 1981, Gowda et al., 2014, Moore and Sears, 1994, Olynyk and

254 Sharpe, 1982, Schmocker et al., 2015, Stein et al., 1996). However, one study revealed minimal improvements in 255 symptoms, non-compliance, and aggravation of symptoms after 2 months of hospitalization (Yalug et al., 2007).

Recommendations: Despite the abnormal nature of this problem, only six research studies suggested 257 recommendations to improve treatment or assessment of xylophagia. Studies have highlighted the absence of 258 standardized medication regimens or psychotherapeutic interventions for treating xylophagia. According to Gowda 259 (2014), support from family, provision of residential care, as well as fostering personal, social and environmental 260 strengths may be beneficial for such individuals. Likewise, another research study highlighted the need for taking a 261 detailed history of individuals presenting with such symptomatology (Spaniolas et al., 2010). Authors also suggested 262 the inclusion of foreign body ingestion for differential diagnosis of abdominal pain (Bakhshaeekia et al., 2009). The 263 need to address nutritional deficiencies for preventing further complications and more research studies to address 264 management options was recommended by three included studies (Schmocker et al., 2015, Stein et al., 1996, Yalug 265 et al., 2007).

\section{Discussion}

Our meta-synthesis found that precipitation of xylophagia; co-morbid psychiatric disorder; outcomes of 268 xylophagia; treatment options comprising medical care, psychological care, counselling, and duration of recovery 269 are the most critical points have been discussed. The serious complications of xylophagia include bowel perforation, 270 mercury poisoning, and in one case, death (Bakhshaeekia et al., 2009, Blinder and Salama, 2008, Olynyk and 271 Sharpe, 1982, Klein et al., 2014). Included studies also show a complex interplay of factors that might be involved 272 in xylophagia such as, modelling of this behavior, traumatic experiences during childhood and adolescence, 273 reinforcement and maintenance of this behavior through escape learning, insufficient attention from family 274 members, problematic relations with members of family, and irrational beliefs about body image (Bharti et al., 2015, 275 Callinan and O'Hare, 1988, Fisher, 2014, Gowda et al., 2014, Stein et al., 1996, Yalug et al., 2007). The findings

276 support socio-cultural as well as biopsychiatric factors in etiology, treatment, and prevention of xylophagia 277 specifically, and eating disorders generally. 
Pica is often reported as a disorder of childhood (Blinder and Salama, 2008, Dumaguing et al., 2003, Klein et

279 al., 2014), making up 25-33\% of the cases reported worldwide (Gowda et al., 2014); with incidents rates reportedly

280 decreasing with age. However, our findings revealed that the majority of cases $(68 \%)$ are adults, with one geriatric

281 patient (Dumaguing et al., 2003). This again points to the underlying cause of pica seen in most of these cases,

282 which is iron-deficiency. There is also the fact that many patients feel ashamed to admit to such behavior (Spaniolas

283 et al., 2010, Bakhshaeekia et al., 2009), a factor also observed in patients in our studies, thus delaying diagnosis until

284 adulthood when severe complications occur. Additionally, children are rarely referred for psychiatric consultations,

285 further delaying the appropriate diagnosis. Thus, Hergüner et al suggested that children should be sent for

286 psychiatric assessments in the absence of underlying medical conditions, OCD, or a family history of OCD; and

287 when iron-deficiency anemia and pica are resistant to iron therapy (Hergüner et al., 2008).

\section{Potential impact of culture and geography}

There were a total of 11 countries involved, with the majority of cases reported in developed countries (i.e.,

29012 respondents) (Callinan and O'Hare, 1988, Fisher, 2014, Graham, 1976, Keeling et al., 1987, Klein et al., 2014,

291 Moore and Sears, 1994, Olynyk and Sharpe, 1982, Schmocker et al., 2015, Spaniolas et al., 2010, Uretsky, 1974)

292 compared to developing countries (i.e., 7 respondents) (Bakhshaeekia et al., 2009, Bharti et al., 2015, Gowda et al.,

293 2014, Stein et al., 1996, Yalug et al., 2007, Fotoulaki et al., 2007). This discrepancy might be a result of more

294 sufficient medical access and knowledge regarding pica as a disorder in developed countries. In a study determining

295 the prevalence rates of psychiatric morbidity in children and adolescents in India where pica is one of the diagnoses,

296 those in urban slum areas had the lowest prevalence rates compared to those in urban areas. This phenomenon might

297 be due to the absence of awareness pertaining to significant psychiatric issues, greater acceptance for deviance,

298 worsened living conditions and the occurrence of various stressors (Srinath et al., 2005). A study by Kettaneh et al

299 also found that being non-European was an independent risk factor for pica, with the authors suggesting that the low

300 incidence in Europeans was either because pica is rare in these patients, or due to the unwillingness to admit to pica

301 because of cultural traits (Kettaneh et al., 2005). As previously mentioned, in some ethnic groups, pica is culturally

302 acceptable, such as in Turkey and Africa where women were encouraged to eat clay to increase their fertility (al-

303 Kanhal and Bani, 1995, Derman et al., 2005).

\section{Underlying etiologies}


The majority of patients in the included studies had either iron deficiency or iron deficiency anemia (IDA).

306 This parallels clinical reports as well as findings in the literature that have pointed to the role of iron deficiency, and

307 not necessarily IDA, in the development of pica (Olynyk and Sharpe, 1982, Lumish et al., 2014, Hergüner et al.,

308 2008). Indeed in the study by Foutulaki et al, the pica was due to IDA secondary to celiac disease (Fotoulaki et al.,

309 2007), which damages the small intestine where iron is absorbed; and is nonresponsive to iron therapy (Freeman,

310 2015). One theory postulated restoring, which describes pica as the body's reaction to deficiency (Klein et al.,

311 2014). This then underlines the importance of first excluding and treating underlying and organic causes of pica

312 before initiating psychiatric therapy (Fotoulaki et al., 2007, Dumaguing et al., 2003). There is however debate as to

313 which came first, with some authors arguing that the consumption of non-nutritive substances in itself led to a loss

314 in appetite which then results in iron deficiency. This was seen in the Callinan paper where cardboard chewing was

315 believed to render fullness which in turn resulted in reduced food intake, consequently impairing iron absorption

316 (Callinan and O'Hare, 1988). It is also postulated that the consumption of these materials may have resulted in an

317 inhibition of iron absorption, thus leading to iron deficiency (Moore and Sears, 1994). Nevertheless, in most of the

318 cases studied in the present meta-synthesis, individuals with iron-deficiency were cured or at least showed

319 improvement in xylophagia after treatment with iron supplementation. However, although a possible relationship

320 between pica and iron-deficiency has been shown, for now, the mechanism is still unclear (Callinan and O'Hare,

321 1988, Chisholm Jr and Martín, 1981, Moore and Sears, 1994, Olynyk and Sharpe, 1982, Schmocker et al., 2015).

A few patients had intellectual disabilities, which supports previous reports that pica is more prevalent in

323 patients with mental disabilities, including having a higher mortality rate (Dumaguing et al., 2003, Klein et al., 2014,

324 Hergüner et al., 2008). Indeed it was noted that worldwide $10-15 \%$ of those with pica have learning disabilities

325 (Gowda et al., 2014). It has been postulated that this is due to diminished impulse regulation, which is a critical

326 clinical characteristic in pica (Gundogar et al., 2003, Stein et al., 1996). The Stein patient had a comorbidity of OCD

327 (Stein et al., 1996), while other patients reported symptoms of compulsions (Schmocker et al., 2015, Yalug et al.,

328 2007, Moore and Sears, 1994); which again parallels previous findings which have attributed pica to OCD or

329 obsessive-compulsive traits (Gundogar et al., 2003, Dumaguing et al., 2003, Bharti et al., 2015). Indeed in instances

330 where iron therapy failed, the use of a selective serotonin reuptake inhibitor was shown to be effective (Bharti et al.,

331 2015, Gowda et al., 2014, Yalug et al., 2007). Other reported predisposing factors include schizophrenia (Gowda et 
332 al., 2014, Hergüner et al., 2008), seen in two cases (Dumaguing et al., 2003, Klein et al., 2014); as well as those with 333 a family history of pica, also seen in two cases (Schmocker et al., 2015, Bharti et al., 2015).

\section{Recommendation for early prevention}

Early detection of xylophagia can help in preventing complications (Singh et al., 2015). As primary prevention, pica should be screened by conducting prevalence surveys, direct observation, stool checks, medical 337 history review, interviewing caregivers, and using screening scales such as the Behavior Problem Inventory in 338 clinical programs and residential facilities (Williams and McAdam, 2012). Those who work where they will interact

339 with people with pica should also be taught about what pica is, the dangers of ingestion of such non-food substances 340 and the prevention strategies (Williams et al., 2009). Family members can also play a role by paying closer attention 341 to patient's behavior, and seeking medical advice immediately if any unusual habits are observed. Parents should 342 also periodically check for any tooth deterioration that might be a result of pica behavior (Singh et al., 2015).

\section{Implications for future research, policy and practice}

This meta-synthesis shows that there are many challenges associated with diagnosing pica because of limited data on its characteristics, medical and psychological assessments, and management. Patients also often present with nonspecific signs and symptoms which may make it hard to detect as well as lead to misdiagnosis and unnecessary treatment (Bharti et al., 2015). This is aggravated by the fact that most patients conceal this behavior and seek medical assistance only after complications occur (Spaniolas et al., 2010), as seen in three cases (Bharti et al., 2015,

349 Schmocker et al., 2015, Graham, 1976); or a proper history could not be obtained, especially in cases of intellectual 350 disability or children (Bakhshaeekia et al., 2009). Various biopsychiatric and sociocultural components have been 351 shown in this review (i.e., familial factors, maintaining factors, co-morbid conditions, psychological problems as 352 outcomes and treatment options) which support the notion that these aspects operate simultaneously in additive, 353 multiplicative, and/or transactional ways. Thus by being cognizant of socioeconomic factors, as well as detecting 354 xylophagia in the early stages, prevention can be achieved and complications can be avoided. More clinical 355 examples are also required to analyze whether pica is more prone to happen in developing or developed countries, as 356 there is a possibility that the cases in developing countries are not reported because of poor access to medical 357 resources and/or naivety towards the characteristic of pica. 
Currently, the treatment for xylophagia is limited, and in most cases, patients are treated with oral iron

359 therapy, antidepressants, or by surgically removing the intestinal bezoars. From a medico-legal perspective, the

360 focus of treatment should be on the main disorder and correcting the causal deficiencies or emphasizes the

361 complication (Moore and Sears, 1994). In some cases, a combination of antipsychotic medication and cognitive

362 behavior therapy is opted (Knecht, 2000).

363 Overcorrection procedures have also been used, but only with the institutionalized patients. The fact that pica

364 is associated with obsessions and compulsions also suggest the need for behavioral treatment (Dumaguing et al.,

365 2003). Further studies, however, are still warranted to investigate the effectiveness of other possible treatments. As it

366 pertains to the substance consumed, it is important to gather information on the specific type that was consumed in

367 terms of brand names, as different brands of the same product may contain different materials, which could lead to

368 different outcomes. In the same vein, while it may all come under the umbrella term of xylophagia, consuming

369 pages of a book would have different consequences from consuming toilet paper. Thus explored and collected

370 information collected should be as specific and detailed as possible (Young et al., 2008).

371 The unusual intake of foreign inedible substances by medical imaging and post-mortem examination with

372 concurrent non-existence of role of external party or influence of medication, illegal drugs, or intoxicating

373 substances, allows an effective explanation of the findings in the background of a complicated biopsychosocial

374 clinical picture. As pica is not commonly known and often asymptomatic, patients might continue practicing the

375 habit until complications occur. As such, there should also be a concerted effort to promote the awareness of pica

376 and its possible consequences to both the public and health professionals. More well-designed trials should also be

377 carried out to understand the characteristics and risk factors of xylophagia in order to facilitate early detection and

378 prevention, as well as diagnosis.

\section{Limitation}

There are some limitations to this meta-synthesis. One limitation was the lack of in-depth exploration of the 381 phenomenon in the included studies. Studies did not explain the results of psychological assessment in details, and 382 there was an absence of follow-up monitoring to confirm the efficacy of treatments offered. Furthermore, the term 383 "xylophagia" was rarely used in the articles; instead, the specific substance consumed was mentioned, possibly 384 increasing the difficulty in retrieving related studies as xylophagia encompasses a wide range of substance that can 
385 be consumed. Out of 18 studies included in this meta-synthesis, 15 studies were case reports, showing a dearth of 386 empirical studies with detailed qualitative or mixed-methodology to highlight the underpinnings of xylophagia.

\section{Conclusions}

The commonly reported causes and triggers of xylophagia are behavior modelling through vicarious learning 389 and post-traumatic disorder suffered during childhood and adolescence. It has been found that xylophagia is often 390 associated with other diseases such as iron-deficiency and various psychiatric disorders. A positive effect of patient 391 and family members undergoing psychology counselling or cognitive behavior therapy in reducing stress and 392 enhancing coping skills thus avoiding self-damaging behaviors has been established. However, out of the 18 393 included studies, only four employed psychotherapy. Similarly, standardized medication regimens for treating 394 xylophagia are still not available and further research is still required to better understand the disease. Furthermore, 395 there must be a thorough assessment of medical, conceptual and explorational histories for any indication of pica 396 that may assist in post-mortem examination and may also give relevant details of linked medical and psychiatric 397 problems. This thorough assessment can help to overcome the chances of overlooking or misdiagnosis due to the 398 presence of transient or mild symptoms or the occurrence of overlapping symptoms.

\section{Compliance with Ethical Standards}

\section{Disclosure of potential conflicts of interest}

401 All authors have no conflict of interest.

\section{Acknowledgments}

403 None

\section{$404 \quad$ Funding}

405 This research received no specific grant from any funding agency in the public, commercial, or not-for-profit 406 sectors. 
408

ACHESON, D. W. 1999. Foodborne infections. Curr Opin Gastroenterol, 15, 538-45.

ADVANI, S., KOCHHAR, G., CHACHRA, S. \& DHAWAN, P. 2014. Eating everything except food (PICA): A rare case report and review. Journal of International Society of Preventive \& Community Dentistry, 4, 1-4.

AL-KANHAL, M. A. \& BANI, I. A. 1995. Food habits during pregnancy among Saudi women. Int J Vitam Nutr Res, 65, 206-10.

APA 2013. American Psychiatric Association. Diagnostic and statistical manual of mental disorders: DSM-5, Washington; London, American Psychiatric Publishing.

BAKHSHAEEKIA, A., HOSSEINI, S. M., RAZMI, T. \& SHAMSAEEFAR, A. 2009. Bowel perforation by crumpled paper in a patient presenting with acute abdominal pain. Saudi $J$ Gastroenterol, 15, 52.

BARROS, J. L., CABALlERO, A., RUEDA, J. C. \& MONTURIOL, J. M. 1991. Foreign body ingestion: Management of 167 cases. World Journal of Surgery, 15, 783-788.

BHARTI, A., MISHRA, A. K., SINHA, V., ANWAR, Z., KUMAR, V. \& MITRA, S. 2015. Paper eating: An unusual obsessive-compulsive disorder dimension. Ind Psychiatry J, 24, 189.

BHATIA, M. S. \& GUPTA, R. 2009. Pica responding to SSRI: An OCD spectrum disorder? The World Journal of Biological Psychiatry, 10, 936-938.

BLINDER, B. J. \& SALAMA, C. 2008. An Update on Pica. Psychiatric Times, 25, 66-73.

BLOCH, Y., LAUDER, A. \& RATZONI, G. 2005. How many pins? A case report of a girl who swallowed more than 50 straight pins in a suicide attempt. De Gruyter.

BYARD, R. W. 2000. Accidental childhood death and the role of the pathologist. Pediatric and developmental pathology, 3, 405-418.

BYARD, R. W. 2014. A review of the forensic implications of pica. Journal of forensic sciences, 59, 1413-1416.

BYARD, R. W. 2017. Death by food. Forensic Science, Medicine and Pathology.

BYARD, R. W., MOORE, L. \& BOURNE, A. J. 1990. Sudden and unexpected death-a late effect of occult intraesophageal foreign body. Pediatric pathology, 10, 837-841.

CALLINAN, V. \& O'HARE, J. A. 1988. Cardboard chewing: cause and effect of iron-deficiency anemia. Am J Med, 85, 449.

CAMPBEll, R., POUND, P., POPE, C., BRITTEN, N., PILL, R., MORGAN, M. \& DONOVAN, J. 2003. Evaluating meta-ethnography: a synthesis of qualitative research on lay experiences of diabetes and diabetes care. Soc Sci Med, 56, 671-684.

CANGIR, A. K., TUG, T. \& OKTEN, I. 2002. An unusual foreign body in the esophagus: report of a case. Surg Today, 32, 523-4.

CHISHOLM JR, J. C. \& MARTÍN, H. I. 1981. Hypozincemia, ageusia, dysosmia, and toilet tissue pica. J National Med Assoc, 73, 163.

DALAL, P. P., OTEY, A. J., MCGONAGLE, E. A., WHITMILL, M. L., LEVINE, E. J., MCKIMMIE, R. L., THOMAS, A. C., COOK, C. H., PAPADIMOS, T. J., REILLEY, T. E., BERGESE, S. D., STEINBERG, S. M., STAWICKI, S. P. \& EVANS, D. C. 2013. Intentional foreign object ingestions: need for endoscopy and surgery. J Surg Res, 184, 145-9.

DECKER, C. J. 1993. Pica in the mentally handicapped: a 15-year surgical perspective. Canadian journal of surgery. Journal canadien de chirurgie, 36, 551-554. 
452

453

454

455

456

457

458

459

460

461

462

463

464

465

466

467

468

469

470

471

472

473

474

475

476

477

478

479

480

481

482

483

484

485

486

487

488

489

490

491

492

493

494

495

496

497

DERMAN, O., ÖKSÜZ-KANBUR, N., YENICESU, İ. \& K1N1K, E. 2005. Iron deficiency anemia in a group of Turkish adolescents: Frequency and contributing factors. De Gruyter.

DUMAGUING, N. I., SINGH, I., SETHI, M. \& DEVANAND, D. P. 2003. Pica in the Geriatric Mentally Ill: Unrelenting and Potentially Fatal. Journal of Geriatric Psychiatry and Neurology, 16, 189-191.

ERWIN, E. J., BROTHERSON, M. J. \& SUMMERS, J. A. 2011. Understanding qualitative metasynthesis: Issues and opportunities in early childhood intervention research. $J$ Early Interv, 33, 186-200.

FEDERMAN, D. G., KIRSNER, R. S. \& FEDERMAN, G. S. 1997. Pica: are you hungry for the facts? Connecticut medicine, 61, 207-209.

FISHER, C. 2014. A Case of Gastritis in a Patient with Paper Pica. . G. Clinical Vignettes/Case Reports (A Clinical Vignette is an abstract with 5 or fewer cases and without methodology).

FOTOULAKI, M., PANAGOPOULOU, P., EFSTRATIOU, I. \& NOUSIA-ARVANITAKIS, S. 2007. Pitfalls in the approach to pica. European Journal of Pediatrics, 166, 623-624.

FOXX, R. M. \& MARTIN, E. D. 1975. Treatment of scavenging behavior coprophagy and pica) by overcorrection. Behaviour Research and Therapy, 13, 153-162.

FREEMAN, H. J. 2015. Iron deficiency anemia in celiac disease. World Journal of Gastroenterology : WJG, 21, 9233-9238.

GLICKMAN, L. T., CHAUDRY, I. U., COSTANTINO, J., CLACK, F. B., CYPESS, R. H. \& WINSLOW, L. 1981. Pica patterns, toxocariasis, and elevated blood lead in children. The American journal of tropical medicine and hygiene, 30, 77-80.

GOWDA, M., PATEL, B. M., PREETI, S. \& CHANDRASEKAR, M. 2014. An unusual case of xylophagia (paper-eating). Ind Psychiatry J, 23, 65.

GRAHAM, P. 1976. Stercoraceous perforation of the pelvic colon--an unusual complication of pica. Medical J Australia, 2, 385.

GUNDOGAR, D., DEMIR, S. B. \& EREN, I. 2003. Is pica in the spectrum of obsessivecompulsive disorders? General hospital psychiatry, 25, 293-294.

GUPTA A, RAJPUT S, MADUABUCHI G \& KUMAR P 2007. Sponge eating: is it an obsessive compulsive disorder or an unusual form of Pica? . Acta Paediatr, 96, 1853-4.

HERGÜNER, S., ÖZY1LD1R1M, İ. \& TAN1D1R, C. 2008. Is Pica an eating disorder or an obsessive-compulsive spectrum disorder? Progress in Neuropsychopharmacology \& Biological Psychiatry, 8, 2010-2011.

HINES, L. 2013. The treatment views and recommendations of substance abusing women: A meta-synthesis. Qual Soc Work, 12, 473-489.

JACOB, B., HUCKENBECK, W., BARZ, J. \& BONTE, W. 1990. Death, after swallowing and aspiration of a high number of foreign bodies, in a schizophrenic woman. Am J Forensic Med Pathol, 11, 331-5.

JENSEN, L. A. \& ALLEN, M. N. 1996. Meta-synthesis of qualitative findings. Qualitative Health Res, 6, 553-560.

JOHNSON, B. E. 1990. Pica. In: WALKER, H. K., HALL, W. D. \& HURST, J. W. (eds.) Clinical Methods: The History, Physical, and Laboratory Examinations. 3 ed. Boston, MA: Butterworths.

KAR, S. K., KAMBOJ, A. \& KUMAR, R. 2015. Pica and Psychosis - Clinical Attributes and Correlations: A Case Report. Journal of Family Medicine and Primary Care, 4, 149-150. 
KEELING, P. J., RAMSAY, J. \& SHAND, W. S. 1987. Pica, paper, and pseudoporphyria. Lancet, 2, 1095.

KETTANEH, A., ECLACHE, V., FAIN, O., SONTAG, C., UZAN, M., CARBILLON, L., STIRNEMANN, J. \& THOMAS, M. 2005. Pica and food craving in patients with irondeficiency anemia: a case-control study in France. Am J Med, 118, 185-188.

KLEIN, A., SCHRÖDER, C., HEINEMANN, A. \& PÜSCHEL, K. 2014. Homicide or suicide? Xylophagia: a possible explanation for extraordinary autopsy findings. Forensic Sci Med Pathol, 10, 437-442.

KMET, L. M., LEE, R. C., COOK, L. S., ALBERTA HERITAGE FOUNDATION FOR MEDICAL RESEARCH, A., HEALTH TECHNOLOGY ASSESSMENT, U., UNIVERSITY OF, C., FACULTY OF, M. \& CALGARY HEALTH, R. 2004. Standard quality assessment criteria for evaluating primary research papers from a variety of fields, Edmonton, Alberta Heritage Foundation for Medical Research.

KNECHT, K. 2000. Pica. Die unbekannte Essstörung. Psychol Praxis, 23, 37-40.

KRUGMAN, S. D., LANTZ, P. E., SINAL, S., DE JONG, A. R. \& COFFMAN, K. 2007. Forced suffocation of infants with baby wipes: a previously undescribed form of child abuse. Child abuse \& neglect, 31, 615-621.

LEVINE, M. P. \& SMOLAK, L. 2014. Paradigm clash in the field of eating disorders: a critical examination of the biopsychiatric model from a sociocultural perspective. Advances in Eating Disorders, 2, 158-170.

LOOTS, D. P. \& DU TOIT-PRINSLOO, L. 2016. A fatal outcome of pica. Forensic Sci Med Pathol, 12, 108-12.

LUMISH, R. A., YOUNG, S. L., LEE, S., COOPER, E., PRESSMAN, E., GUILLET, R. \& O’BRIEN, K. O. 2014. Gestational Iron Deficiency Is Associated with Pica Behaviors in Adolescents. The Journal of Nutrition.

MCLOUGHLIN, I. J. 1988. Pica as a cause of death in three mentally handicapped men. The British Journal of Psychiatry, 152, 842-845.

MOORE, D. F. \& SEARS, D. A. 1994. Pica, iron deficiency, and the medical history. The American journal of medicine, 97, 390-393.

NICOLAI, T. \& REITER, K. 2004. Notfalltherapie der akuten Fremdkörperaspiration beim KindAspiration of a foreign body in young children. Notfall \& Rettungsmedizin, 7, 501506.

NOBLIT, G. W. \& HARE, R. D. 1988. Meta-Ethnography: Synthesizing qualitative studies United States, SAGE Publications.

OLYNYK, F. \& SHARPE, D. 1982. Mercury poisoning in paper pica. New England J Med, 306.

PARAKH, J. S., MCAVOY, A. \& CORLESS, D. J. 2016. Rapunzel syndrome resulting in gastric perforation. Ann R Coll Surg Engl, 98, e6-7.

PARRY-JONES, B. \& PARRY-JONES, W. L. 1992. Pica: symptom or eating disorder? A historical assessment. The British Journal of Psychiatry, 160, 341-354.

ROSE, E. A., PORCERELLI, J. H. \& NEALE, A. V. 2000. Pica: common but commonly missed. The Journal of the American Board of Family Practice, 13, 353-358.

SAUVAGEAU, A. \& RACETTE, S. 2006. Female Autoerotic Deaths-Still Often Overlooked. Medicine, science and the law, 46, 357-359.

SCHAPER, A., HOFMANN, R., BARGAIN, P., EBBECKE, M., DESEL, H. \& LANGER, C. 2003. Cocaine body packing: Infrequent indication for laparotomy. Chirurg 47, 10741075. 
SCHMOCKER, R. K., DAVID YU GREENBLATT MD, M. \& GREENBERG, J. A. 2015. An unusual case of obstruction after roux-en-y gastric bypass. Am Surg, 81, E8.

SIMPSON, E., MULL, J. D., LONGLEY, E. \& EAST, J. 2000. Pica during Pregnancy in LowIncome Women Born in Mexico. Western Journal of Medicine 20-24.

SINGH, H., AGARWAL, S., SINGH, V., REHMAN, R. \& PATWARDHAN, N. 2015. Pica disorder with autism: Intervention in dental settings. $J$ Res Adv Dent, 4, 281-291.

SPANIOLAS, K., OU, S., FINDEIS-HOSEY, J., MONSON, J. R. \& SALLOUM, R. 2010. Paper pica: an unusual cause of colonic ischemia. J Gastrointest Surg, 14, 1065-1066.

SREETHARAN, S. S., PREPAGERAN, N. \& SATWANT, S. 2004. Unusual migratory foreign body in the neck. Singapore medical journal, 45, 487-488.

SRINATH, S., GIRIMAJI, S. C., GURURAJ, G. \& SESHADRI, S. 2005. Epidemiological study of child $\&$ adolescent psychiatric disorders in urban $\&$ rural areas of Bangalore, India. Indian J Med Res, 122, 67.

STEIN, D. J., BOUWER, C. \& VAN HEERDEN, B. 1996. Pica and the obsessive-compulsive spectrum disorders. $S$ Afr Med J, 86, 1586-8, 1591-2.

TOKER, H., OZDEMIR, H., OZAN, F., TURGUT, M., GOZE, F., SENCAN, M. \& KANTARCI, A. 2009. Dramatic oral findings belonging to a pica patient: a case report. International dental journal, 59, 26-30.

URETSKY, B. 1974. Paper bezoar causing intestinal obstruction. Arch Surg, 109, 123-123.

VELITCHKOV, N. G., GRIGOROV, G. I., LOSANOFF, J. E. \& KJOSSEV, K. T. 1996. Ingested foreign bodies of the gastrointestinal tract: retrospective analysis of 542 cases. World J Surg, 20, 1001-5.

WALKER AND M.C. ROBERTS (ed.) 2001. The Handbook of Clinical Child Psychology New York: NY: John Wiley \& Sons.

WALSH, D. \& DOWNE, S. 2005. Meta-synthesis method for qualitative research: a literature review. J Adv Nurs, 50, 204-211.

WALSH, D. \& DOWNE, S. 2006. Appraising the quality of qualitative research. Midwifery, 22, 108-119.

WICK, R., GILBERT, J. D. \& BYARD, R. W. 2006. Café coronary syndrome-fatal choking on food: an autopsy approach. Journal of Clinical Forensic Medicine, 13, 135-138.

WILLIAMS, D. E., KIRKPATRICK-SANCHEZ, S., ENZINNA, C., DUNN, J. \& BORDENKARASACK, D. 2009. The clinical management and prevention of pica: A retrospective follow-up of 41 individuals with intellectual disabilities and pica. $J$ Appl Res Intellect Disabil, 22, 210-215.

WILLIAMS, D. E. \& MCADAM, D. 2012. Assessment, behavioral treatment, and prevention of pica: Clinical guidelines and recommendations for practitioners. Res Dev Disabil, 33, 2050-2057.

YALUG, I., KIRMIZI-ALSAN, E. \& TUFAN, A. E. 2007. Adult onset paper pica in the context of anorexia nervosa with major depressive disorder and a history of childhood geophagia: a case report. Prog Neuropsychopharmacol Biol Psychiatry, 31, 1341-2.

YAMAGUCHI, Y., TERASHIMA, M., NAKAO, A., YOSHIE, N., FUJISAKI, N., YAMADA, T., OKAMOTO, A., HASHIMOTO, A. \& KOTANI, J. 2014. To remove or not remove? Twenty or more sewing needles in the gastrointestinal tract. Acute Med Surg, 1, 250-251. YOUNG, S. L., WILSON, M. J., MILLER, D. \& HILLIER, S. 2008. Toward a Comprehensive Approach to the Collection and Analysis of Pica Substances, with Emphasis on Geophagic Materials. PLOS ONE, 3, e3147. 
590 ŽGANJER, V., ŽGANJER, M., ČIZMIĆ, A., PAJIĆ, A. \& ŽUPANČIĆ, B. 2011. Suicide 591 attempt by swallowing sponge or pica disorder: a case report. Acta Medica (Hradec $592 \quad$ Kralove), 54, 91-93.

593 ZHAO, Y. \& ENCINOSA, W. 2011. An Update on Hospitalizations for Eating Disorders, 1999 594 to 2009 Rockville, MD.: Agency for Healthcare Research and Quality.

595 ZOUROS, E., OIKONOMOU, D., THEOHARIS, G., BANTIAS, C. \&

596 PAPADIMITROPOULOS, K. 2014. Perforation of the cecum by a toothpick: report of a 597 case and review of the literature. J Emerg Med, 47, e133-7. 